\title{
Representative Government in the Era of Improved Communication
}

\section{Benjamin Barrowes}

Dartmouth College, Hanover, NH, USA

Email: Benjamin.e.barrowes@dartmouth.edu

How to cite this paper: Barrowes, B. (2019). Representative Government in the Era of Improved Communication. Open Journal of Political Science, 9, 349-372. https://doi.org/10.4236/ojps.2019.92019

Received: February 22, 2019

Accepted: April 12, 2019

Published: April 15, 2019

Copyright $\odot 2019$ by author(s) and Scientific Research Publishing Inc. This work is licensed under the Creative Commons Attribution International License (CC BY 4.0).

http://creativecommons.org/licenses/by/4.0/

\begin{abstract}
Technology is allowing communication to become inexpensive, ubiquitous, secure, and instantaneous, in the process transforming individual lives and societies. Representative government was conceived in an era of laborious, slow, insecure, local, and high-cost communication modalities. These modalities imposed burdensome but inescapable limitations on both the representatives who were entrusted to aggregate and adjudicate public sentiment while making decisions on the behalf of others, as well as the public who faced trust crises, participation barriers, and ignorance of facts and issues. This paper explores positive and negative consequences that improved communication has for representatives. Consequences for a better educated and informed citizenry often with unprecedented discretionary time are also examined. Conclusions include deliberate power divestment on the part of representatives and an open source government model for citizens.
\end{abstract}

\section{Keywords}

Representative Government, Open Source Government, Citizen, Electromagnetics, Improved Communication

\section{Introduction}

Representative government and democracy trace their history back over 2500 years ago to the Greek city states. Appointing or electing representatives of groups of people allowed for differentiation and specialization. The politician could dedicate time and energy to representing the people and the people could use their time and energy for other pursuits. This agreement between the people and the representative was a necessary compromise between the two extremes of anarchy on one side with no one working toward societal improvement and stagnation on the other side with all people being politicians only with no care- 
givers, farmers, blacksmiths, merchants, warriors, and so forth. Representatives tended to centralize power and decision making, aggregating the demands and concerns of the people, interpreting their interests, but politicians also acted as sieves of information back to the people, protecting their own interests, and sometimes acting on their own best judgement in defiance of the people's will because they "knew better." Accountability thus became uneven and intermittent due to the filter of information the representative represented.

One principal driver of this forced compromise and specialization was the available modes of communication, at first only oral, then written though with difficulty and high cost. Until Maxwell finished the theoretical groundwork that allowed the use of electromagnetics for long-distance communication (Maxwell, 1873; Kong, 2004; Kong, 2005), humans were limited to their local and immediate experiences of sight and sound. Representatives thus became to be elected based on their skill of manipulating sights and sounds in their local environment with a heavy emphasis on oratorical skills and personal charisma and attributes. Non-politicians were forced to decide their vote based on restricted and sparse information concerning the issues and the politician which most often resulted in a subjective emotional vote, especially considering the lower average educational level of most pre- $20^{\text {th }}$ century voters. Having no alternative, representatives were selected based on their self-limited "virtues and talents" (Jefferson, 1813).

Nature and pre-Maxwellian communication had imposed limits on the speed, cost, security, trustworthiness, effort, and area of effect of oral and written communications. Until the widespread use of movable type, written communication, which could impact a much broader audience than oral communication alone, was the purview of only the noble and wealthy. The barriers to education and communication stratified classes with power over information settling on the elite. Representative government was largely abandoned for centuries after the Roman Empire tradition until constitutional monarchies rose and eventually modern republics such as America and France were born. Power divestment from the few to the many was and is a protracted and treacherous odyssey. Yet even within these modern republics, citizens and representatives alike relied on archaic and readily abused communication modalities; communication was insecure, impermanent, unverifiable, local, and top-down (see Table 1).

Humans realized light speed long-distance communication with the electric telegraph in the early 19th century (Prescott, 2013). Electromagnetic waves, though not fully understood yet, allowed experimenters to act in one place with a noticeable effect even thousands of miles away, at long last realizing real-time communication beyond one's immediate locale. The effects of this communication began to transform society, business and politics almost instantly. Morse cautioned telegraph operators to be careful to not introduce bias into messages and foresaw that instantaneous communication would be used for both good and evil (Elon, 2006). However, even with the telegraph, the total world daily electromagnetic data rate was under a few Megabytes per minute. 
Table 1. Communication Methods and typical characteristics, with the demarcation dates in column 2 corresponding to patents issued to Wheatstone, Edison, Tesla, Farnsworth, and Berners-Lee respectively (dates from Wikipedia).

\begin{tabular}{cccccc}
\hline \multicolumn{5}{c}{ Communications Modalities } \\
\hline Modality & Inception & Area of Effect & Persistence & Participants & Direction \\
\hline Oral & Prehistoric & 10 's of meters & Momentary & One-to-few & any \\
Written & $3500 \mathrm{BC}$ & Any & 100 's of years & One-to-few & Any \\
Newspaper & $16^{\text {th }}$ century & 100's of km & Decades & Few-to-many & Top-down \\
Telegraph & 1837 & 1000 's of km & Momentary & One-to-few & Top-top \\
Telephone & 1876 & Any & Momentary & One-to-few & Any \\
Radio & 1898 & Any & Momentary & Few-to-many & Top-down \\
Television & 1927 & Any & Momentary & Few-to-many & Top-down \\
IC & 1989 & Any & Indefinite & Any-to-any & Any \\
\hline
\end{tabular}

The telegraph was superseded by the telephone, then television and pre-internet technologies such as the FAX machine. The reach, scope, and direction broadened from a momentary, one-to-few modality (speech), to decentralized IC which persisted indefinitely, could affect any number of people nearly instantaneously, and was free and comparatively easy to use. These technologies affected an increasing number of people in broadening ways: socially, educationally, and politically. Trust and judgement were easier to give when one's own eyes and ears could witness remote events. News and information both from abroad and from within one's inner circle flowed like water, freely and unhindered compared to the archaic communication modalities of the past. The world became smaller and the audiences became larger. Yet these modes of communication principally enabled information to flow from the top down, to be consumed by the masses, from a few with power to the many without power. Methods of communication that produced information that were available to the general public reached only a few other individuals: one-to-few modes of communication like the telephone or self-produced VHS tapes. Vote seeking representatives relied even more on charisma as the real-time audiences welled.

With the advent of the cold war era developed internet in the late 20th century, citizens finally had access to inexpensive, fast, and trustworthy one-to-many communication. Text could be sent from a single source to any and all who desired to read it. Audio and then video publication became too cheap to meter on sites such as Flickr, Vimeo, and Youtube. Information flowed on progressively fast and reliable data networks spanning the globe both wirelessly and on cables crisscrossing the planet. Total internet traffic expanded exponentially from an estimated one TeraByte per month in 1990 to 122 ExaBytes in 2017 (Wikipedia Contributors, 2019) with video streaming consuming nearly $58 \%$ of the total internet bandwidth in 2018 (Sandvine, 2018). While politicians have made increasingly efficient use of top-down information methods in areas such as social me- 
dia, campaigns still operate largely with an outlflow of information and potential representatives still largely rely on charisma and their own limited capabilities for votes.

Noteworthy among the technological advances occurring in tandem with the internet is the opening and collaborative development of source codes and wikis. Early open development efforts by Donald Knuth writing the TeX typesetting system in 1979 (Knuth, 2012) and Richard Stallman releasing the GNU operating system in 1983 (Stallman, 2000) led to more widely known free open source software (FOSS) such as Netscape, Linux, and Wikipedia being developed and released to the public (Tozzi, 2017). This new model for developing software of freely giving away the source code tree without price, but with an implicit request for assistant in improving the code, allowed many people to participate in creating content in a secure, controlled environment. Even though any single person on the development team for an open source software project may not understand or comprehend the entire code suite, each person could contribute to a given part of the code suite, with the distributed contributions of the several members coalescing to form a finished product. Contributions such as new code suggestions or bug fixes are submitted, then traverse a well-defined process of confirmation, utility assessment, triage, workaround, scrutiny, and implementation on teams often spanning many countries consisting of hundreds or thousands of individuals who may have never met each other in the flesh. Hundreds of people have contributed to Octave (Eaton et al., 2009), including the author, since its inception in 1988 while Linux boasts roughly 15,600 active developers (Torvalds \& Diamond, 2001; Corbet, 2017). Importantly, FOSS contributors need to spend only as little as a few minutes per day on their donated development time instead of working on the code as a full-time job.

This paper explores ramifications of one-to-many, too-cheap-to-meter, fast, secure, trustworthy, far-reaching, collaborative communication, hereafter collectively referred to as IC (improved communication), on politics. Specifically, consequences and propositions for elected representatives will be discussed in Section 2, after which consequences and proposals regarding these new communication modalities on the citizenry, including the introduction of open source government (OSG), will be analyzed in Section 3. This will be followed by general observations about some ideals of governance in Section 4 with a conclusion in Section 5.

\section{Improved Communication and Representative Government}

\subsection{Representatives Changing Interaction with Citizens}

IC presents several challenges to traditional politicians with their reliance primarily on their own capabilities and traditional top-down communication strategies. Because the representative's statements and behavior can be rapidly compared to prior statements and behavior, mistakes and inconsistencies are more 
quickly noticed and carry graver consequences. Even offhanded non-policy opinion statements or actions can have serious ramifications for a representative and/or their campaign to be (re)elected. Candidates and campaigns typically react with a tightening of official information, but more should be done in this area if representatives want to guard against the slightest errors. The extreme solution is for representatives to cease making extemporaneous statements except under very controlled circumstances. This would mean that representatives should not answer sudden questions, make no impromptu or off-the-cuff comments, and cease to rely solely on their own intellect and capabilities for answers when they do respond to questions. The representative should instead defer to a greater authority, the authority of Open Source Government (see Section 3) for answers and solutions.

Somewhat paradoxically, representatives and high-level managers in the government should flood information outlay by wearing body cameras streaming their moment to moment interactions whenever they are acting in any official capacity. Public servants should wear these body cameras similar to police officers wearing body cameras so that actions and statements may be scrutinized after the fact. In this way, a single statement will have less of an effect than many statements over time because the entire pattern of statements and behavior can be pointed to in the face of one anomalous or difficult to understand communication. Personal or classified information should be streamed to classified channels but still recorded for perusal by those with the proper clearance. With this flood of information, frequent reminders should be made that deliberation and discussion with their associated musings and ideas are not final policy. As well, no external policy deliberations should occur if the bodycam is not recording the interaction. Similarly, unless there is sufficient reason to classify information, all information from public agencies should be by default released to the public immediately: budgets, emails, memoranda, proposed actions, deliberations, etc., like a bodycam for the organization itself. When representatives both flood communication pathways with streaming their acts of public service and rely less on local, improvised interaction, individual charisma will be deemphasized in favor of the value of the representative's ideas, civility, and ability for rational discussion and compromise.

Instead of relying on one's own capabilities, knowledge, charisma, and other qualities in the moment for communication, politicians should instead rely on open source government (OSG) which will be discussed further in Section 3. Few questions and problems are so critical as to have no time for reference or collaboration regarding the solution. OSG-based answers to questions, learning materials, discussion points, and proposed solutions should be consulted by representatives under all possible circumstances. Adopting this style of communication would render debates unnecessary, for example. Before IC, debates provided one of the only methods for communication between candidates and the citizenry. The charisma and wit of a candidate when answering questions produced an archaic emotional response in those viewing the spectacle which would 
lead to their underinformed voting for one candidate or another based on factors that may not correlate with overall net benefit (ONB, see Section 4).

IC has also obviated much of the need for money in politics. In the past, money has been of greater importance because money roughly correlated with greater communication. Because of IC, communication is inexpensive to the point that politicians should refuse campaign contributions. Political parties, action committees, companies, and citizens may exercise their right to free speech, but the representatives need no longer accept money or any other compensation with the inevitable strings attached. This policy is in line with current law regarding federal employees. The so-called "doughnut" rule limits the benefits (gifts) that federal employees can receive from contractors to a minimal amount such as the cost of it doughnut in order to avoid conflicts of interest with that contractor. Federal employees often have the power to spend the government's money which contractors want, and therefore any benefit to the federal employee from the contractor represents a potential ethical problem. In the same light, politicians have the power to spend their favor to people or corporations, and so should not receive anything worth more than a doughnut from anyone or any organization. Instead of donations to the representative, or anyone close to the representative, citizens should instead donate time and effort to OSG as well as encourage their acquaintances to do the same.

One way to consider the role of news organizations historically is as a conduit of communication from sources (e.g. politicians) to citizens. News organizations pay people to collect information and then present the collected information, increasingly with agenda-ridden commentary, to citizens who do not have time to collect and interpret that corpus of information on their own. Because of this role that news organizations had in conveying information to citizens, representatives in the past accommodated news organizations' requests and granted special privileges to the press. However, IC enables politicians and citizens to bypass this archaic form of interpreted communication on the part of news organizations. Distributed groups of citizens participating in OSG can contribute their time and effort to replicate this information and communication pathway. In addition, representatives can bypass news organizations by not preferring employees of news organizations, but instead randomly choosing to be interviewed or have a discussion with any citizen who desires it. Instead of an anchor from a major news channel, a representative may randomly select a sixth-grader wanting to interview the representative for their school paper. IC will allow the content of the interview, with the representative referring to OSG produced answers and ideas, to be broadcast around the world without the interpretive lens of any news organization interfering.

Representatives of the people now hold an immense amount of power and influence compared to their beginnings in ancient Greece. Representing 50 or 1000 people whose names and family members you know is considerably different than endeavoring to amalgamate the combined opinions of millions of people based on one person's judgement. Instead of this impossible task, representatives 
should instead voluntarily divest their august power and defer to the people they ostensibly aim to represent. IC now enables many citizens to communicate to one representative with the many opinions and personalities mixing and organically coalescing around sound ideas and solutions that maximize overall net benefit. IC-enabled OSG allows citizens to have a voice without a single person's judgement to act as a filter of their voices. Considering this new paradigm, a natural question is then, what power or role is left for a representative? Though representative's power is critically diminished under OSG, they are not left devoid of all power. A representative's role in the era of IC falls into two categories: leading discussions and maintaining the responsibility that their personal vote amounts to a small percentage of the will of the people.

\subsection{Representative Responsibilities}

Representatives must continue to be discussion leaders and to contribute ideas to OSG as one of the few whose full-time job is to strive for ONB. Representatives will likely possess the most knowledge of the entire government structure, will initially have the most facts surrounding topics, and will likely have the most up-to-date information. Therefore, they must guide and lead discussions on OSG website(s), in randomized interviews, in communities, in homes, in businesses, everywhere they go as a public servant, but always remembering to consult OSG first and continuously, to wear a body camera, to not rely solely on their own persona and charisma, and to not allow anonymity and mob-like behavior. These conditions will result in a decisive divestment of power from the representative to the citizenry, with the charisma and capabilities of the representative declining in significance and being supplanted by the rising importance of the knowledge and ideas of the citizenry.

In this spirit, a representative becomes a facilitator and a discussion leader, but has one other major responsibility. The politician should voluntarily subsume their own will and follow the will of the people who make their will known through OSG (see Section 3.2). Once the will of the citizens is combined in OSG, when the time comes for the definitive, formal vote in political session, the representative should pledge to follow the will of the citizens via OSG. In cases where the representative disagrees with the will of the people, that person should pledge to deviate from that collective will by only up to a certain percentage, up to a maximum of $5 \%$ (for example). Thus, after the citizenry collect their facts, knowledge, ideas, and opinions, then makes their will known, the representative must choose that course of action at the formal vote unless that representative opposes the will of the people and the people's will is split with less than 5\% difference. For example, if the citizenry chooses "yea" for a bill or motion with a tally up to $52.5 \%$, but $47.5 \%$ of the citizenry chooses "nay" on that topic, then the representative can still choose "nay" because the difference between the "yea"s and the "nay"s is $5 \%$ or less. Any larger difference would force the representative (by their own pledge) to vote "yea" in deference to the will of the people. OSG Establishes a more direct line of influence from the people to the government, 
from the bottom up, via IC. The tallying method used in OSG need not be plebiscitical, though this is certainly an option. Instead, extra weight in the tally should be given to those who score high on peer review for bias, civility, and knowledge (see Section 3.2).

These two responsibilities then remain with the representative: leading discussions and assuming up to a $5 \%$ formal voting responsibility after the will of people through OSG has been made known.

\subsection{Discussion Principles and Ideals}

The preeminent mode of human to human communication will continue to be discussions, whether they are oral, written, or IC. Unlike computers with sequential procedures, central processing, and specific memory, humans have evolved with decentralized processing, parallel procedures, and distributed memory (Whitworth \& Hokyoung, 2012). Given the lengthy but indispensable growing process humans inescapably traverse when presented with a new concept, the quintessential discussion has endured for millennia as the crude yet optimal method for learning and maturation. During a discussion, it is suggested that representatives as well as the citizenry follow accepted rules of civil dialogue. For example, representatives should follow Martin Luther King's six steps of nonviolent social change as well as his six principles of nonviolence (King, 1959; Center, 2019). Note that these steps and principles should apply to nonphysi$\mathrm{cal} /$ emotional violence as well as physical violence. Failure to follow rules such as these in the age of IC will quickly be recognized due to the widespread reach of IC and those individuals sporting such behavior will be appropriately scored under OSG. The following rules should also be considered during discussion:

- To the greatest extent possible, only one claim or topic should be addressed at any given moment, for a given discussion.

- OSG answers should be referenced before the representative attempts to answer and OSG sources should be adhered to during the discussion.

- All participants should speak for roughly $1 / N$ of the total time where $N$ represents the number of participants in the discussion, unless a discussion leader is allowed more than $1 / N$ time by the participants.

- Participants should not continue for more than a decided upon amount of time, maybe 20 seconds, on their turn.

- Interruptions should only occur in the case of pain or danger.

- Every attempt should be made by each participant to ensure that the other participants enjoyed the interaction/discussion.

- Interactions should be positive for all participants when possible, not teasing, not belittling, not dismissing, etc.

These discussion principles and ideals will tend to instill trust and goodwill between those who employ them. Those who do not engage using this approach should be rated accordingly under OSG.

Given a suitable environment, humans have displayed remarkable creativity and innovation in bettering their condition. While politics and governments can 
provide this environment, science and technology have provided the means whereby the living conditions of humans have improved. In this light, an early question that should be addressed when discussing issues under OSG should be: how will science and technology eventually solve this problem or obviate this fight? Once needs are defined, resources can be allocated to the most promising directions of research and inquiry. In addition, agreeing on the long-term goals and directions regarding a problem often helps the various factions come together at the outset.

As an example, consider the timely problem of abortion. What is the technology or science that could eventually solve for obviate this fight over abortion between sincere factions? One possibility is the following: if there existed free, long-term, easily reversible, side-effectless, and $100 \%$ effective conception control followed by mandatory DNA testing for all conceptions to promote accountability, would that not obviate most of the contention surrounding abortion? Such a conception control does not currently exist except as research (Waller et al., 2017; Long et al., 2019), but if such conception control did exist and was provided free to all citizens, all but a fraction of a percent of abortions currently performed would be unnecessary. The scope of the problem would be reduced considerably along with the emotion and intensity. Having agreed on the long-term solution, the journey to that solution can be shortened through directed research, alleviating some of the burden or fighting and giving hope to all parties.

One more discussion precept worth mentioning is the difference between speaking about individuals and speaking about groups, or in other words, speaking statistically. It can be a problem in both directions. If one individual in a discussion wants to limit the discussion to be about a single individual, but others in the conversation are trying to speak regarding a group (statistically), misunderstandings can occur. Likewise, if one person speaks statistically while others are expecting a response tailored to an individual, the speaker can sound cold and stoic. Representative must consider the entire statistical group they represent because IC will carry their message far and wide, but also need to be conscientious about the concerns of the individuals in their immediate surroundings.

\section{Modern Communication and Citizens}

IC has transformative power to change how citizens interact with their representatives in government. In addition to relying less on local sights and sounds from politicians which produce transient subjective emotional responses, citizens may now participate in government in ways that were impossible before IC. For example, citizens can now participate in OSG, co-opting the similar model from open source software endeavors. Even though each citizen may not understand the entire set of political issues that the representative may face, a citizen may be an expert on one aspect or issue and be able to contribute profitably on that issue in a few minutes per day, rather than devote their full energies to poli- 
tics. Citizens may be able to research a particular claim made by another party and present evidence to either support or refute that claim. Citizens may also rate each other as well as rate news organizations and other politicians according to their perceived biases, their civility, and their knowledge. Citizens are no longer restricted by a top-down flow of information but are enabled by OSG to participate and meaningfully contribute to the political process from the bottom up because of IC.

Examples of mass involvement by amateur contributors in grand projects have demonstrated the theoretical viability of extensive direct volunteer involvement in government. While early open source software projects were decried as foolhardy, individuals have shown the usefulness and capability of the interested volunteer model. With tens of thousands of contributors, Wikipedia now represents the largest encyclopedia known to man, referenced millions of times per day. Citizens now have the opportunity to take more control of governments through discussions, learning, maturing, thinking, reasoning, rating: IC-enabled open source government.

\subsection{Citizens Changing Interaction with Representatives}

Human experience has shown that people behave better and make decisions more beneficial to society when their identity is known during their actions. Indeed, the presumptive and enabling notion on the part of most any criminal is that of anonymity. During interactions, anonymity is associated with the possibility of mob like behavior in humans which often leads to demeanor of lower quality and integrity such as bullying, destruction of property, and intimidation. Citizens need to be aware that anonymous communication will be disregarded by their representatives, and only trustworthy secure IC should be considered valid by representatives. Thus, communication on social media sites, statements and comments on websites, all communication should be made with the positive identification of the communicator. This requirement for communication will largely deter rude, mob like behavior because the communicator will be held accountable for their communication. This positive identification capability can be accomplished through biomarkers such as fingerprints, iris scanners, facial recognition, gait recognition, voice recognition, articulatory recognition, and DNA identification, all sealed with unbreakable blockchains. The archaic expectation of anonymity when communicating should perish from the earth.

\subsection{Open Source Government}

IC has enabled a new way for groups to interact and cooperate on goals that would have been too large for any one individual before IC. Scientific research groups typically include individuals from different states and/or countries separated by hundreds or thousands of kilometers, with the individual researchers not meeting each other in person for months at a time. Families that were once more tightly bound geographically can now fluidly scatter to distant locales while still feeling close through IC. And as mentioned above, large groups num- 
bering in the thousands can produce complicated software rivalling the products from the largest companies via open source software techniques and source control framework such as CVS and mercurial. In all these cases and many more, IC has enabled disparately located people to cooperate and communicate using one-to-few, one-to-many, and many-to-many methods, often without price, in full trust and security, instantaneously, without the necessity for power and influence, producing coordinated cohesive results which were impossible for non-august citizens only a few decades ago.

Open Source Government builds on this foundation provided by IC to build policy and government through the many contributions of disparately located citizens. Citizens participate in OSG voluntarily and in their discretionary time dedicating as much of their resources as they desire. OSG is built line upon line, beginning with small distinct verifiable and secure contributions such as a rating (see below), a verification, some research, an idea, a review, a comment, a proposal, gaining knowledge, and other modes of participation. Upon these building blocks, citizens can produce coordinated and cohesive results much greater in significance than possible for one person alone to produce.

\subsubsection{Bias and Civility Ratings}

One critical method by which citizens can contribute to OSG is through ratings. Under OSG, citizens rate the works produced by other citizens for bias and civility (or other agreed upon measures like accuracy) on some suitable symmetric scale such as the real numbers between some predetermined limits $[-S, \cdots, S]$ with zero corresponding to unbiased (in either direction) and neutral civility respectively. For this rating, negative and positive refer to some suitable definition such as left and right, Democrat and Republican, extreme one direction or extreme the other direction, and so forth as long as the scale is clearly defined. Citizens' ratings may not be anonymous and must be secured through unique and unbreakable identifiers using technologies such as blockchains. These ratings inform other citizens about the bias and civility of works produced by other citizens and thereby about the owner of those works. In order to contribute, citizens do not need to digest the full corpus of another person's works. One individual rating of just a single work, when combined with others' ratings of other single works by that same producer, when taken together, will result in an overall rating for the entirety of that producer's works (articles, news stories, comments, videos, tweet, post, $\cdots$ any produced IC). A person owns and adopts the bias and civility ratings of their works by proxy because it is too difficult for one human to see into the heart of another human clearly. Producers of works are humans as well, and they rate others' works resulting in a sparse but sufficient mutually intertwined system.

When citizens and their works acquire ratings, and these ratings are known to the producer of the works as well as anyone else, citizens can quickly understand what bias and civility to likely expect from that person. And to interpolate, when an organization (company, staff, political administration, religious group, news 
organization, etc.) employs people with known ratings, organizations then adopt and own an overall rating based on the ratings of those in their employ. In this way, the bias and civility of citizens and organizations will be clearly known to themselves and to all others. Artificial intelligence currently cannot produce useful ratings of bias and civility and must not replace humans performing these ratings in the future. It is vital that humans rate other humans because the rating process itself refines and improves the human doing the rating to better understand others. Instead, the utility of AI should be in aggregating and sifting information, analyzing bodycam video, finding related questions and answers on OSG websites, and so on, but humans need to rate, adjudicate, and form conclusions.

Humans are imperfect and thus their ratings of others will all contain imperfections and inaccuracies both inadvertent and intentional. In this light, an appropriate weighting and normalization system should be adopted that collates the contributions of the rating population, so that "true" biases result, even as shifting culture redefines the scales. The following tallying procedure represents one possible method, but the topic of optimal tallying methods which minimizes bad actors and results in true average ratings will be left to a future paper.

Individuals are not rated directly, but they adopt overall ratings based on their works, or in other words, products. Each work, be it an idea, an article, a question, a comment, a tweet, etc., may be rated by others, but each work may be weighted differently when accounting for a person's rating: a 20-page article may be weighted heavier than a short tweet (see $\beta_{z}$ below). The bias rating for a person is unique compared to all other ratings for that individual because bias influences all ratings given by that person, and that person's ratings may be consistently biased compared to the rest of the population. The population rating a given article are themselves biased, there may be more people in that rating population biased in one direction over the other, and there may be bad actors trying to artificially sway the ratings in one direction or another. To guard against these pitfalls, appropriate rating tally methods must account for the overall bias rating of the reviewer, the number and bias distribution of the reviewing population, and that rating population's bias ratings with respect to the mean rating.

Consider a population, $\boldsymbol{P}$, consisting of $N$ citizens where each member produces up to a maximum of $W$ works. Let the weights given to each type of work product be denoted by $\beta_{z}$ where $\mathrm{z}=$ \{idea, comment, article, video, tweet, etc.\} and total possible types $Z$. Personnmay rate the $w^{\text {th }}$ work of any other person $p$ with a rating category $x$ where $x=\{m, a, b, c$, etc. $\}$ (see below). We construct the four-dimensional matrix $\boldsymbol{R}$ with the first index of $\boldsymbol{R}$ corresponding to ratern, the second index corresponding to rate $p$, the third index of $\boldsymbol{R}$ indexes each work or product of person $p$, and the fourth dimension indicating the rating category. Because people do not rate their own work, it is understood that $\boldsymbol{R}(n, n,:,:) \equiv 0$ for all $n$. Also construct matrix $\delta$ with the same structure as $\boldsymbol{R}$ which consists of 1's in that entry if person $n$ has rated the $w^{\text {th }}$ work of person $p$ in category $x$ and zero otherwise. Person $n$ acquires characteristic ratings 
$\boldsymbol{R}_{n}=R_{n, m}, R_{n, a}, R_{n, b}, R_{n, c}, \cdots$ derived (see below) from others' ratings of that $n^{\text {th }}$ person's works, where $R_{n, m}$ corresponds to the $n^{\text {th }}$ person's merit rating, $R_{n, a}$ corresponds to the $n^{\text {th }}$ person's accuracy rating, $R_{n, b}$ corresponds to the bias rating, $R_{n, c}$ to the civility rating, and so on for each rating category.

With these definitions of a population $(\boldsymbol{P})$, their acquired ratings $\left(\boldsymbol{R}_{n}\right)$, and the population's ratings of each other's products $(\overline{\boldsymbol{R}})$, we can propose to construct a mutually coupled rating system that aims to trend toward the "true" ratings in the sense that that rating reflects society's current opinion. $R_{n, x}$ could be a weighted mean of other people's ratings

$$
R_{n, x}=\frac{\sum_{i=1}^{N} \sum_{k=1}^{W} \boldsymbol{R}(i, n, k, x) \beta_{x}}{\sum_{i=1}^{N} \sum_{k=1}^{W} \boldsymbol{\delta}(i, n, k, x) \beta_{x}}
$$

where the $k$ in $\beta_{k}$ is understood to index into possible $z$ values, and the role of $\delta$ is to properly count ratings of zero in the matrix $\boldsymbol{R}$ in the denominator. Products from each person (for product $k$ from person $i$ in category $x$ ) also acquire characteristic ratings which could be a simple mean as follows

$$
\operatorname{mean}_{i} \boldsymbol{R}(i, j, k, x)=\langle\boldsymbol{R}(i, j, k, x)\rangle_{i}=\frac{\sum_{i=1, i \neq n}^{N} \boldsymbol{R}(i, j, k, x)}{\sum_{i=1, i \neq n}^{N} \boldsymbol{\delta}(i, j, k, x)}
$$

for all $j, k$, and $x$ resulting in a three-dimensional matrix after this average is taken over the first dimension.

In order to encourage honest participation, we introduce a possible feedback system that weights ratings from unbiased raters with heavier weights than ratings from biased raters. This would modify Equation (1) to become

$$
R_{n, x}=\frac{\sum_{i=1}^{N} \sum_{k=1}^{W} \boldsymbol{R}(i, n, k, x)\left(S_{x}-\left|R_{i, b}\right|\right) \beta_{x}}{\sum_{i=1}^{N} \sum_{k=1}^{W} \boldsymbol{\delta}(i, n, k, x)\left(S_{x}-\left|R_{i, b}\right|\right) \beta_{x}}
$$

where $S_{x}$ is the scale of the category $x$. Here, the weighted average is modified so that the more biased a rater is, the less their opinion counts towards rating others. Similarly, Equation (2) could be modified to reflect this linear negative feedback method as

$$
\langle\boldsymbol{R}(i, j, k, x)\rangle_{i}=\frac{\sum_{i=1, i \neq n}^{N} \boldsymbol{R}(i, j, k, x)\left(S_{x}-\left|R_{i, b}\right|\right)}{\sum_{i=1, i \neq n}^{N} \delta(i, j, k, x)\left(S_{x}-\left|R_{i, b}\right|\right)}
$$

Other methods of rating and of feedback in the system can be envisaged, of course. But the idea here is to introduce a system that can quickly recognize meritorious products and people, while just as quickly identifying and labeling inaccurate or biased products as an indication to others. Using this method, "fake news" as well as "biased news" as well as "news anchors" who are really opinion 
commentators, etc., can all be identified so that people who have not yet rated a given product can both know others opinion about the current product and know what to expect regarding future products. Bad actors will also be quickly identified, although $\boldsymbol{R}_{n}$ should be calculated based on a finite time window from the recent past, say 6 months, in order to give people a chance to reform. Ratings can also be grouped according to geography, age, gender, and other markers because people will have to be positively identified in order to participate in OSG.

One more marker needs mentioning with regard to citizens participating in OSG, the knowledge marker. The intent is to have a way to gauge the knowledge of person $n$ regarding a certain product, say on the topic of the environment, or firearms, or the constitution, or ethanol, or the trade deficit, etc. This marker is harder to calculate considering the difficulty for one person to conclusively perceive another person's mind, thus Equation (1) for the knowledge category is ineffective. However, under OSG, a tally could be kept of products regarding a certain topic of question that a person has digested. Better methods need to be developed to verify "digestion" of a product... a quiz regarding a video or article for example, or perhaps the knowledge rating could simply be based on how many products a person has rated that have to do with that category. This should be investigated.

\subsubsection{Ideas and Solutions OSG Website}

IC has enabled the agglomeration of ideas, solutions, and answers in a way never before experienced in the history of mankind. Information now flows from any-to-any quickly and relatively easily. A good idea, a funny meme, a catchy tune, or an interesting video can reach huge segments of the population within days or even hours. Knowledge from one person can solve a problem for millions of other people also within days or even hours such as when someone solves a bug in a large open source software effort of figures out a clever way to fix a certain part on a car. In this new era of IC, another major role for citizens in open source Government is to participate in OSG websites that aim to discuss issues and questions while helping all in the community to gain knowledge. These websites, in the wild and uncontrolled as it were, exist independent of the government, yet feed into the combined knowledge and idea base of the representatives of the people.

The concept of a town meeting, kept alive in New England mainly with its small population rural towns, is the concept of a citizen government, in which for a day, the citizen becomes part of a designated legislative body. In these town meetings, everyone has a voice, everyone is known with a positive identification, and a moderator possessing high standards of civility leads the discussion. Citizens learn of issues and present their ideas to their fellows, all with the same core desire to improve their circumstances and their town at the same time, abstracted and so ably painted by Norman Rockwell in his work, "Freedom of Speech" (Rockwell, 1943). Now with IC, the entire represented population of 
citizens can become a perpetual town meeting so to speak as volunteers even with only a few minutes of discretionary time per day. And just like at a town meeting, those who choose to speak present their ideas and solutions, and everyone has a voice, and everyone is known with a positive ID.

Unlike town meeting, there is no one moderator, but there is room for all act as moderators for each other because the time constraints are not as restricting as in an in-person meeting. And all participants can act as raters of each other. Good ideas are naturally rated for merit and recognized by the community, gradually percolating upward and outward to get more exposure to the wider community. Reading, listening, and watching others' ideas and solutions as well as digesting agreed-upon facts become the basis for one's knowledge rating. Thus, 15 minutes of experiencing and OSG website could consist of reading several comments on an idea or question that an individual has interest in, reading and then evaluating the bias of a news article relating to that question, and subsequently offering a new idea for the solution of that question or problem. From that 15 minutes of effort, IC enables any number of other people to benefit from that one person's small, simple, but profound actions.

Representatives can then utilize the citizens' highest rated solutions and ideas under OSG, when answering questions for example during interviews, when debating bills and legislation in bodies of government, and when pondering how to maximize ONB. These OSG products of knowledge, ideas, and solutions will act as a well of living humanity ready to benefit the most people and cause suffering to the fewest people. It is on these OSG websites that representatives must lead the discussion by having a prominent part of the webpage for each topic or question devoted to the representative's insights and thoughts. A representative will have time to peruse dozens of questions or topics per day while gaining knowledge, refining their own biases, and being civil. The representative will tend to be an expert on many topics and have the vision of the entire policy tree, noting and evaluating the indispensable contributions from the citizens that they represent, similar to the way in which open source software leaders evaluate the contributions of their unpaid software developers that may only work $15 \mathrm{mi}$ nutes a day.

Trending solutions and ideas should also have prominence on OSG websites. Solutions and ideas based on verified data should be presented in a pyramidal fashion, with concise answers at the top proceeding to more in-depth answers as the foundation. Citizens can use available media formats to present knowledge (that will get rated for bias and accuracy) to others while simultaneously consuming and rating others' contributions. In this way, the idea behind a town meeting can be expanded via IC into the idea of a constituent wide congregation of interested volunteers, all working to maximize ONB, not just their own benefit. As a corollary, those citizens with the best knowledge, civility, accuracy, knowledge, bias and any other ratings that OSG chooses to employ can be invited to participate in formal staff and policy meetings with the representative, either in person or through IC. In return for this volunteer OSG effort, citizens 
can expect their representative to formally vote with the majority of the sentiment (tallied in an agreed-upon manner) of the OSG participants, except in cases where the representative chooses to exercise their 5\% discretion. Representatives and citizens thus have a wholly new relationship under which power is wrested and divested from the representative and given back to the citizens from whence it came.

\subsection{Trust and Security}

The burden of proof in a free-as-possible society has been a heavy weight indeed on the shoulders of justice. Even with modern IC, crime committed in anonymity is far too difficult to prove, and the guilty often sneer as they are let free. Modern forensics is helping to forge a more accountable society, but trying to ascertain the veracity of people's decades-old memories without tangible evidence is a near hopeless endeavor, for example. History has sometimes sided with the accuser, sometimes with the accused, and in some strange cases even inanimate objects and animals have been held on trial (Kadri, 2007). Proof, with its companions trust and security, is historically a difficult mountain to climb, but IC is enabling this too to be transformed.

With positive identification via biomarkers as described above, new methods enabling absolute trust and security regarding ownership is now possible. Without middlemen, blockchain technology uniquely and uncircumventably identifies ownership of everything from actions like voting to authorship of an article. Technology such as blockchains have enabled secure voting in several elections (Linver, 2018), and currently allow decentralized currency and transactions with crypto currencies such as Bitcoin and Ada (Cardano, 2018). All products under OSG must be positively identified and tied to the owner, products such as votes, ideas, solutions, articles, videos, ratings, and any other fruit of that person. Decentralized entities (especially not the government itself) can then tally these products for any person to see, including representatives.

\subsection{Summary}

Citizens have historically been unable to meaningfully participate in the political decision making of their representatives because of poor communication modalities. Specialized politicians have acted as filters of information, relied on their charisma and oratorical talents, and wielded power without sufficient involvement from and accountability to the citizens for too long. IC now has the potential to upend the traditional separation of power between representatives and the people who elect them by allowing any-to-any communication that at once matures the participants and fosters the best solutions and ideas. Instead of asking for money or time, representatives will rather ask for OSG participation from those they represent, thus transferring much of the burden of governing off the shoulders of the representative back onto the people. Citizens will grow to occupy their rightful place as the producers of government, instead of the consumers of government. 


\section{Ideals of Governance}

A person constitutes the most complicated system known to man. There are thousands if not millions of aspects to any one person including aspects about their character, their background, their family, their experiences, their attitudes, their values, their abilities, their aspirations, their desires, their mistakes, their regrets, their first crushes, their formal and informal schooling, their acquaintances and the list could go on and on. Such complexity cannot be reduced to simple judgments or quick summaries. Flaws and weaknesses coexist in a person along with their strengths and talents. The temptation to dislike the whole person (or family, or organization, or company, or political party, or country, or race, or gender, etc.) with their thousands of aspects based on a smattering of information about a few aspects must be resisted. Instead, people should remember their own incomplete state and forgive the current deficiencies of others.

One conspicuous benefit of IC is the reduced transportation requirement to achieve the same level of communication. Video and audio calls should be used whenever possible to reduce transportation costs including pollution. Further advancements in IC will allow virtual reality to supplant video communication for an even more natural communication experience.

The founding fathers specifically listed three inalienable rights in the Declaration of Independence. Their belief was that governments should secure these rights, then create and maintain an environment where citizens possessed the most possible freedom to exercise these rights. The emphasis is then on the individuals themselves to exercise these inherent rights. In this vein, government can and should help sustain life, but not lifestyle, should foster fair treatment and opportunities, but not force, and should allow maximum freedom for citizens to pursue happiness, but not attempt to provide happiness. When government oversteps these tenets or boundaries, force generally becomes unavoidable. But the seeds of prosperity and peace require effort to germinate. As force replaces freedom, humans tend to exert less effort to improve their own condition and the condition of others because: 1) they would get less benefit from their effort and 2) they would be restricted in enjoying the fruits of their potential success. A government based on ensuring maximum freedom then tends to elicit more effort on the parts of its citizens, and this effort is what helps individuals and societies progress.

Instead of trying to overlegislate behavior, in many cases IC has permitted an alternative approach to promoting accountability in human interaction. Information is the great equalizer. Just as anonymity should be discarded to foster accountability, so should choices be made public via IC if those choices may have a powerful impact on others. As an example, consider the house building process. The construction permitting and oversight process is heavily legislated and regulated even when a person builds their own structure for their own use because of the potential impact on others. Instead of forcing the builder to con- 
form their behavior to the will of legislators, however, choices made by the builder should be documented but otherwise allowed. Upon trying to sell, this information will inform potential buyers of the choices made by the builder (e.g. nonstandard stair heights). The builder can then be held accountable by the potential buyers either through a price reduction or by abandoning the sale. IC provides the means to record and store vast amounts of information which can lead to citizens regulating and governing themselves if they choose to. Freedom for the builder is maintained, but others' safety and rights are also secured through information, not by legislation. This concept of accountability through information instead of legislation could allow greater freedom for individuals and organizations. Currently, the effectiveness of this principle can be frequently observed in the form of the many viral videos showing adverse behavior. Bad actors in these videos are more likely to be held accountable due to the information relating to their behavior being widely known through IC.

Benefits can be maximized most rapidly through individual effort. If one's own efforts are insufficient, either in the short or long-term, then one's family, then community volunteer organizations such as a church may help. Government help may be an option, but disassociated government help has a poor record for long-term problem solving on an individual level. Individuals are usually best poised to help individuals because system optimization is more tractable with fewer people in the group. Bureaucracy helping individuals is sometimes the last resort but should be avoided in favor of the government enabling people to help people. A system under which people can be awarded microgrants for helping others should be considered. The amount and validity of the grantee and the grantor's actions should be based on ratings and ONB, with the least government involvement possible. To ensure accountability, the helping individual should document the help with a bodycam which videos should be randomly checked/rated for validity. Possible topics of microgrants could be taking someone to work, education assistance, drug rehabilitation, health advice, but with the expectation that microgrants should be given only in cases where the above listed other forms of assistance are unavailable. More details on this topic will be left to a future paper.

\subsection{Benefits and Suffering}

Society is an exceedingly difficult system to optimize due to the total complexity of the system, i.e. multiple interacting humans, each with thousands of working parts of their characters and lives. Whenever any group of humans tries to optimize the system artificially, societal and governmental demise then collapse, with the associated inevitable suffering, tends to follow (Soviet Union, Venezuela, several African dictatorships, all known socialist and communist governments). Trying to use force to optimize such a complex system as a society has proven to be beyond the capability of any group of humans, no matter how good the intentions may have been at the outset. Therefore, societies and governments should resist introducing laws (force) that lead to restricted freedom whenever 
possible to allow the system to optimize itself at the most fundamental level possible, the individual. This maximal freedom approach to societal optimization underpins democracies and capitalism, and has been shown to have the most success of any other form of government to increase lifespans, bring the most out of poverty, prevent the most sickness, provide the most food, avert the most wars, etc. than any other form of governance. Until resources are not scarce, expressions of human nature in the form of competition and evolution will necessitate the freedom to attempt optimization on the individual level.

Notwithstanding the success of liberty and freedom for self-optimizing societies, some laws can prove beneficial to more people over more time than the suffering that that law generates. This trade-off of benefits versus suffering brought about by a particular law or action, or Overall Net Benefit (ONB), can be expressed as a notional equation,

$$
\mathrm{ONB}=\int_{t_{0}}^{T+t_{0}} \sum_{n=1}^{N}\left(\mathbb{B}_{n}(t)-\mathbb{S}_{n}(t)\right) \mathrm{d} t
$$

where $t$ is time, $T$ is how long into the future one deigns to consider the consequences of the action, $\mathbb{B}_{n}(t)$ is the benefit for each person $n$ as a function of time, $\mathbb{S}_{n}(t)$ is similarly the $n^{\text {th }}$ individual's suffering as a function of time, and $N$ is the total population under consideration. All conceivable and measurable benefits and suffering should be considered and included in Equation (5). If the $\mathbb{B}_{n}(t)$ and $\mathbb{S}_{n}(t)$, positive real quantities that may vary decidedly between population groups, are not measurable, then the legitimacy of passing and enforcing the action should be seriously and assiduously questioned. The time, $T$, should embrace the long-term (see Section 4.2) with one potential value being set to the average remaining life expectancy of the people under consideration. The portion of the population to consider, $N$, should be selected based on those objectively affected by the proposed action.

Care should be taken to resist oversimplifying and appropriating the definitions of $\mathbb{B}_{n}(t)$ and $\mathbb{S}_{n}(t)$ during the maximization of ONB. In many ways, the definitions of these quantities become a part of the basis of culture and expectations in a society. The definitions can change between countries, regions, races, ethnicities, centuries, etc., but should ultimately be beholden to human nature, with historically proven values informing the explication. Abuse of the precepts entrenched in Equation (5), for example not scoping an appropriate $N$, is the definition of nearly all crime and can readily lead to atrocities including wars of aggression, slavery, apartheid, child labor, and murder. Rights and values intrinsic to humans which exist above governments such as life, liberty, and the pursuit of happiness ought not to be skirted for the benefit/convenience of those in power (i.e. giving more weight to $\mathbb{B}_{n}(t)$ for $n=\{$ leaders $\}$ ). Taking the life and liberty of Jesus and Joan of Arc, for example, or the Japanese exploiting “comfort women (ianfu, 慰安婦)", the KKK lynching black Americans, the abuse of children, or the Nazi practicing eugenics, all display a lack of proper definitions of $\mathbb{B}_{n}(t), \mathbb{S}_{n}(t), T$, and $N$. 


\subsection{Long-Term vs. Short-Term}

Making high level, complex decisions is arguably the defining capability of humans vs. all other animals. Our decision making has well established roots in our evolutionary upbringing as a species, however, and vestiges of these roots often influence our behavior more than we suspect (Kahneman, 2015). One aspect of our evolutionary upbringing that still plagues our thinking is that of decision speed. For thousands of years, necessity has dictated that humans make real-time educated guesses in order to evade the time required to fully acquire a broad understanding of the data inputs and ramifications to many decisions. Humans have used their biological neural nets to arrive at conclusions in a finite amount of time principally because of a lack of IC. As a result of this evolutionary history, with humans so accustomed to rapid decisions, when faced with the task of gathering data and predicting ramifications, many humans alone or in small groups will become impatient and guess at unknowns without resorting to a more time-consuming, reasoned approach based on IC.

IC has now made it possible to gather vast amounts of data and to thoroughly explore the projected ramification space prior to finalizing a decision, many times in the same amount of time it would have taken an individual or even a small group of people to archaically arrive at a pre-IC decision. Using the OSG concept of large groups of citizens providing small but trusted contributions of data, ideas, solutions, proposals, comments, ratings, learning, and so forth, representatives and their staffs can now make policy decisions with much more confidence. This decision-making process may take less time or more time than pre-IC decision making, but the increase in ONB is surely worth the patience required. The responsibility as well as the credit is shared between the representative and the citizenry, but patience and forbearance are key to resisting the temptation to make a hasty, bad decision.

Hasty decisions made arm in arm with impatience often entail unforeseen negative consequences. As an illustration, consider Figure 1 showing typical profiles of happiness (or other measures such as health, freedom, ONB, etc.) as a function of time considering the ramifications of certain types of decisions. The choice of whether to cheat or not on a test will be used to exposit the different curves, though extensive classes of other decisions such as using artificial high inducing drugs non-medically, getting angry and showing it, or deceiving others could be used. And granted, specific cases contrary to the notions in the figure can certainly be expounded, but the attempt here is to speak statistically about broad classes of decisions and not any specific future decision in order to illustrate the point.

The moment of choice begins the graph at the left-hand side. In the present example of whether to cheat on a fair test, the choice presents itself to the test-taker of whether to cheat and increase their score or to not cheat and potentially do worse on the test. The irony is that in the short-term bad decisions often lead to a good outcome for a time. For a cheater, they may actually do better 


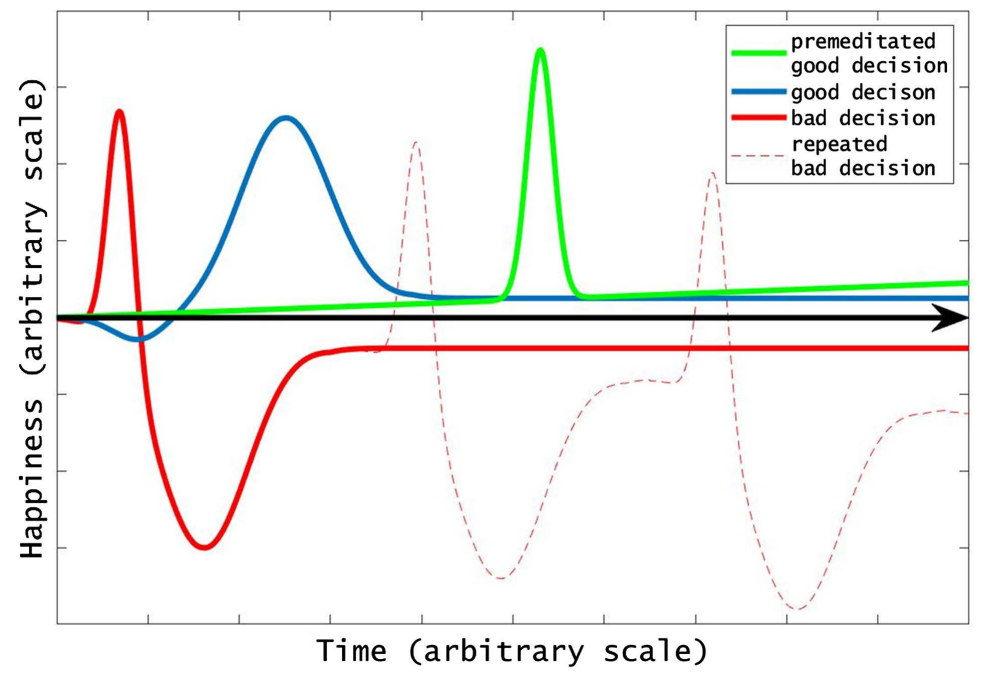

Figure 1. Happiness, or overall health, of an individual or group of individuals as a function of time as a result of the consequences of different types of decisions. The timescale is arbitrary in the sense that the total time could represent anywhere from seconds to centuries.

on the test and be happy for a while. But, the cheater that bought short-term happiness on that test pays a heavy price in the long term by not being prepared for future tests and for difficult choices in the future because they did not strive to improve themselves. This leaves the cheater with long-term negatives in their life resulting in long-term unhappiness. The twin irony is that in the short term, good decisions often result in bad outcomes. In this case, an honest person may do worse on that test and feel bad for a time. However, part of their good decision is to strive for betterment, thus preparing themselves for success on future tests. Therefore in the longer-term, the honest person is happy because they have improved themselves and that happiness remains. Note that habitual cheaters continue to experience short-term highs each time they make their bad choice, but are gradually ruining their long-term success and happiness little by little. The honest person on the other hand builds themselves and their happiness little by little toward a bright and happy future. Note that ONB is positive for "good" decisions and negative for "bad" decisions if the appropriate total time $T$ is chosen, but the inverse is true if the $T$ is too short.

The choice of whether to regularly exercise a reasonable amount can also be analyzed with respect to the curves in Figure 1. In the short-term, exercise is somewhat unpleasant, but yields long-term benefits. Not regularly exercising is rewarding in the short-term because it frees up time for another preferred activity, but long-term negatives can accrue. Self-control and restraint, valuing the expanded longer-term rather than acceding to short-term seductions, applies on the personal level as well as on all levels of human interaction and government. Government overgifting, for example, while attractive for the recipient in the short-term, can lead to dependency and resource depletion for the receiver and giver, respectively. 
The curves in this figure apply to happiness after choice points, but of singular importance is to apply the lessons from these curves to choice points related to freedom. History is replete with examples of well-intentioned individuals deciding to take away freedom from others without their consent. The decision is reached as the freedom-pilferer stands mesmerized by the attractive short-term happiness reward of a "bad" choice frequently forged in the fires of impatience. Neglected or ignored is the medium and long-term negative consequences of less freedom. King George taxed and restricted the 13 colonies without their approval. Millions were forced in communes and five-year plans without considering the impossibility of optimizing large populations. Postbellum Democrat-dominated legislatures institutionalized discrimination via Jim Crow laws restricting the freedom of African and Native Americans. Billions of humans continue to be denied religious freedom by their governments under threat of execution. In all these cases, the medium and long-term adverse negative repercussions of restricting the human yearning for freedom and liberty are severe and enduring.

In addition to these two stereotypical types of choices, the graph shows an even better method of choosing: a premeditated good decision. This type of decision is made with patience and planning to have no short-term negative, a medium-term positive, and the continual improvement going forward. This understanding of the ramifications of choice as a function of time can apply to a wide array of decisions, bills, and actions. OSG tends to enable premeditated good decisions by improving the people participating and accumulating input from the widest range possible, not just from career representatives.

\section{Conclusion}

Archaic political representatives focus on controlling the message or narrative while relying on their own charisma, talents, and virtues. Modern day Improved Communication is transforming representative government by divesting power from representatives who cling to these old-fashioned foci in favor of volunteer citizens producing government rather than consuming it. IC allows any-to-any communication which is inexpensive, instantaneous, secure, and boundaryless. Representatives can no longer rely on self-centered localized sights and sounds to sway the voting citizenry. Instead, IC-enabled Open Source Government allows citizens to contribute ideas, solutions, ask questions, gain knowledge, rate products, and participate in government in their discretionary time. OSG empowers citizens to contribute, participate, and then vote on issues and topics, thus becoming the center of government, whereas the roles of representatives are reduced to leading discussions and carrying up to $5 \%$ of the vote. IC divests power from politicians and, at long last, returns government to the people from whence it came.

\section{Acknowledgements}

I'd like to thank my family for their encouragement and support as well as Fri- 
don Shubitidze and Danney Glaser for the suggestion to put these ideas in writing.

\section{Conflicts of Interest}

The author declares no conflicts of interest regarding the publication of this paper.

\section{References}

Cardano, A. (2018). Cardano Roadmap. https://www.cardano.org/en/home

Center, K. (2019). The King Philosophy_The King Center.

https://thekingcenter.org/king-philosophy

Corbet, J. (2017). 2017 Linux Kernel Report. https://www.linuxfoundation.org/blog/2017/10/2017-linux-kernel-report-highlights-de velopers-roles-accelerating-pace-change

Eaton, J. W., Bateman, D., \& Hauberg, S. (2009). GNU Octave: A High-Level Interactive Language for Numerical Computations. Bristol: Network Theory Ltd.

Elon, U. (2006). Imagining the Internet: A History and a Forecast. http://www.elon.edu/e-web/predictions/150/1830.xhtml

Jefferson, T. (1813). Founders Online. https://founders.archives.gov/documents/Jefferson/03-06-02-0478

Kadri, S. (2007). Trial: Four Thousand Years of Courtroom Drama. Random House. http://www.myilibrary.com?id=433218

Kahneman, D. (2015). Thinking, Fast and Slow.

King, M. L. (1959). Stride toward Freedom: The Montgomery Story. London: Victor Gollancz.

Knuth, D. E. (2012). The TEXbook: ... Describes TEX Version 3.0 .... Upper Saddle River, NJ: Addison-Wesley.

Kong, J. A. (2004). Maxwell Equations. Beijing: Higher Education Press.

Kong, J. A. (2005). Electromagnetic Wave Theory. Cambridge, MA: EMW Pub.

Linver, H. (2018). Blockchain and Elections: The Japanese, Swiss and American Experience.

Long, J. E., Lee, M. S., \& Blithe, D. L. (2019). Male Contraceptive Development: Update on Novel Hormonal and Nonhormonal Methods. Clinical Chemistry, 65, 153-160. https://doi.org/10.1373/clinchem.2018.295089

Maxwell, J. C. (1873). A Treatise on Electricity and Magnetism. Oxford: Oxford University Press.

Prescott, G. B. (2013). History, Theory, and Practice of the Electric Telegraph.

Rockwell, N. (1943). Freedom of Speech. Office of War Information.

Sandvine (2018). Internet Phenomena Report.

https://www.sandvine.com/2018-internet-phenomena-report

Stallman, R. M. (2000). GNU Tools Micellany: A Compendium of GNU Utilities. Lincoln (NE): iUniverse.com.

Torvalds, L., \& Diamond, D. (2001). Just for Fun. New York: Harper Audio.

Tozzi, C. J. (2017). For Fun and Profit: A History of the Free and Open Source Software Revolution. 
Waller, D. et al. (2017). Reversibility of Vasalgel Male Contraceptive in a Rabbit Model. Basic and Clinical Andrology, 27, 8.

Whitworth, B., \& Hokyoung, R. (2012). A Comparison of Human and Computer Information Processing. In Machine Learning: Concepts, Methodologies, Tools and Applications (pp. 1-12). Hershey, PA: IGI Global. https://doi.org/10.4018/978-1-60960-818-7.ch101

Wikipedia Contributors (2019). Internet Traffic-Wikipedia, the Free Encyclopedia. 